\title{
The Parrot Brief: A drawing guide for first-year architecture students
}

\author{
Adriana Cobo \\ School of Architecture \& Construction
}

\section{Description}

The Parrot Brief is an audio drawing guide for first-year architecture students, devised in MP3 format, which received university learning and teaching innovation funding. It is downloadable from the School of Architecture's digital studio, and also available for loan in the Avery Hill library. The guide can be played over and over again, repeating the same text as many times as the user requests, hence the name the Parrot Brief.

Taking advantage of the fact that the students of today are used to carrying portable, personal electronic devices (iPods and sophisticated mobile phones with various sound and image applications), the drawing guide is intended to be a personal companion. The Parrot Brief allows students to replay the content as many times as needed, anytime, anyplace; it complements printed studio briefs (environmentally unfriendly and frequently lost) and studio tutorial sessions. Aimed at improving stage one architecture students' observational drawing skills through sketching, the Parrot Brief is intended to enhance teaching and support the design process through formative sketchbook work. It focuses on enabling students to produce successful year one architectural drawings.

\section{Teaching context}

Within the teaching and learning context of the classroom or design studio, observational drawing is usually left to field trips or dedicated, outdoor drawing sessions. These need to be carefully scheduled with students working together in a group, usually with one tutor and 10 to 20 students. With an MP3 audio guide, observational drawing can be taught outside the classroom. The personal aspects of drawing are supported - students decide themselves when and where to go, and how to use the guide - leading to a higher degree of commitment and concentration.

There are, however, difficulties in teaching using recorded, standardised instructions and guiding someone through a highly, personal, individual task such as drawing. When drawing we aim to communicate our individual expression or style and this can be difficult to achieve if the instructions are too prescribed. As opposed to one-to-one tutorials, where the tutor is giving comments to several students and therefore spending only a few minutes with each person, the audio guide's tutoring voice accompanies the user throughout the whole process of making a drawing. The vocal delivery of the recorded instructions is therefore important, with a playful approach easing the tension for the student, between following instructions and drawing freely.

In their book Drawing for the Artistically Undiscovered, Quentin Blake and John Cassidy (1999) state that the intention of the book is to provide readers with the tools for expressing originally and uniquely their 'you-ness'. They propose celebrating mistakes (often feared by a person who wants to 
start drawing) and provide pencils without erasers to accompany the book. It is important to consider some differences between drawing in architecture (the Parrot Brief is specifically about drawing buildings) and art, the subject of Blake and Cassidy's book. When drawing architecture, there are specific factors to consider, size, proportion, context and fixedness. Drawing people, animals or nature (some of the subjects from Blake and Cassidy's book) calls for a different approach. Capturing the 'soul' of a building or place through drawing may be a harder task than doing the same with animated subjects. If one looks at an architect's sketchbooks and drawings, such as Aldo Rossi's, one discovers powerful renderings of cities and buildings, which reflect personal beliefs and memories. Rossi believed cities were accumulations of personal stories, structures made through fragmented memories and unpredictable events, and this is what he drew throughout his life. Rossi mixed childhood images and personal objects with existing buildings and projects, re-interpreting real views of buildings, places and cities while transforming them into half- fictional, half-real images. His projects, both constructed and not, reflect this combination.

I believe achieving a balance between 'fun' learning experiences, while delivering lasting, essential skills, is at the core of any teaching methodology (and of any tutor's thoughts) and is a difficult task to achieve. I consider this audio guide to be one step on my own journey as a tutor, exploring new techniques and enhancing both my teaching and my students' learning.

\section{Making the guide: Analysis of the process}

I started by doing four drawings myself in order to decode the techniques that I use when drawing. These internal reflections formed the basis of a script for the audio guide which then takes students through the same four drawings. Decoding my own drawing and sketching techniques proved a challenging experience, since it involved me recording a step-by-step process describing the way that I draw (a process that by now has become mostly automatic). However, this was essential in designing a guide that could be used without the direct assistance of a tutor.

Usually, drawing subjects involves a great deal of direct tutoring. It includes monitoring students while they are drawing and commenting on their results right after their drawings are finished. Sometimes students are asked to sketch a view or make drawings of specific subjects as homework and feedback is given through tutorials, with the purpose of developing subsequent drawings. All these techniques involve a learning process based on trial and error, where the students themselves discover techniques, as they practice drawing at home or during monitored, drawing sessions. These teaching methods effectively promote 'individual expression' and result in unique drawings.

As with any audio guide, the tutor is 'replaced' by a recorded voice so her/his role as a witness of a student's drawing process is removed. Therefore, a prescribed set of instructions to be used by anyone in exactly the same way could conflict with students developing their own style. The advantage however, is that the guide represents a half-hour monitored process for each drawing with each student, something which is almost impossible when working with tutorial groups larger than twelve students (equating to six hours of tutorial time per drawing).

\section{Feedback}

The guide was made during the academic year and two of the exercises were tested at the end of it by a group of five people, including students and practitioners. The students who tested the guide were already at the end of the first year of their BA programme so its effectiveness for new 
students, with little experience of drawing architecture, is difficult to assess. Most of the volunteers commented on the guide being prescriptive and said that it prevented them from doing 'their own drawing'. Interestingly enough, when looking at the results, each drawing was very different from any other, even drawings of the same view. All of the drawings showed fine proportions, good size and scale. This proved that it is possible to use the guide as personal tool without producing standardized results. The feedback that I obtained from the volunteers was more useful for adjusting the tone of the guide than for the content on drawing techniques.

The feedback also touched on questions of whether digital briefs could replace traditional tutoring, or act as a useful complement for direct contact time. A combination of both teaching methodologies is the ideal and I believe that the guide is a tool that enhances face-to-face tutorials.

\section{Sample drawings}

London is an endless architectural resource. The guide uses some of the city's iconic locations to take students through the joy of drawing, some results of which are presented here.

These drawings are reproduced with special thanks to my colleagues Elinor Stewart and Alys Williams, and first-year students Ahammed Hussein and Neal Fairman, who volunteered their time and valuable feedback after testing the guide.

\section{The British Museum, South Portico}

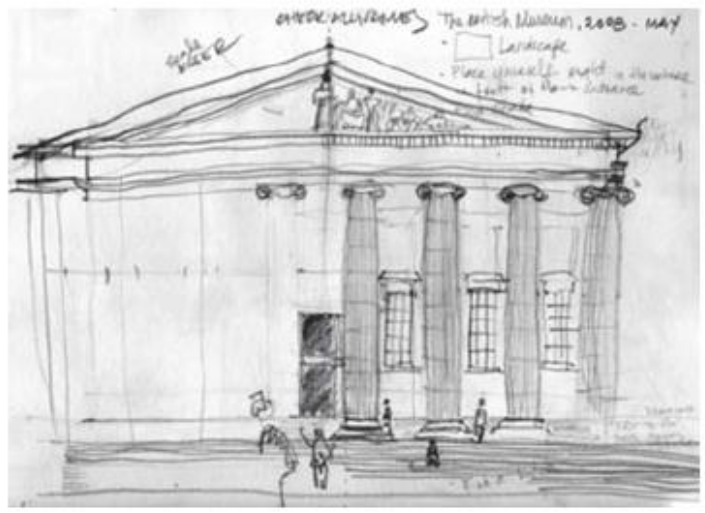

By Adriana Cobo

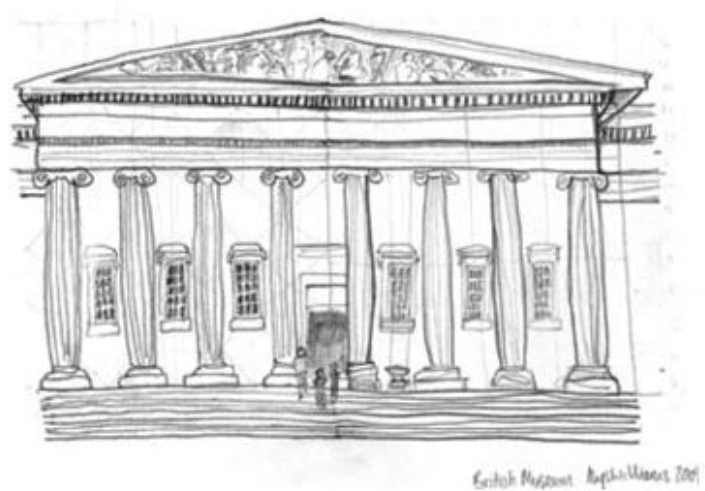

By Alys Williams 


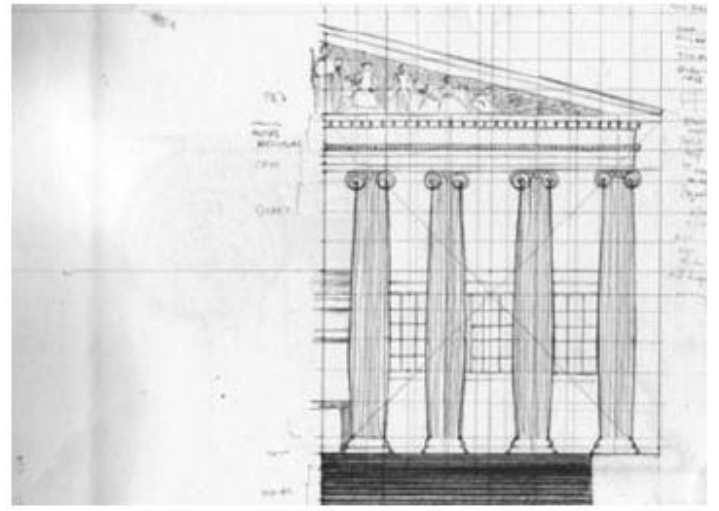

By Ahammed Hussein

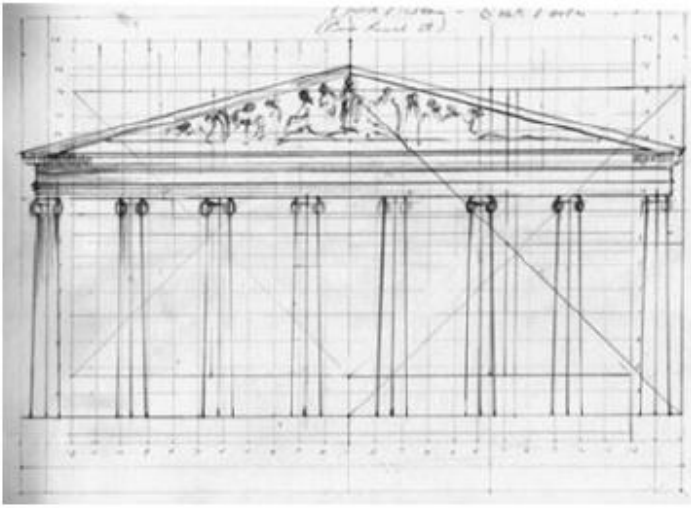

By Neal Fairman

\section{The Canary Wharf skyline}

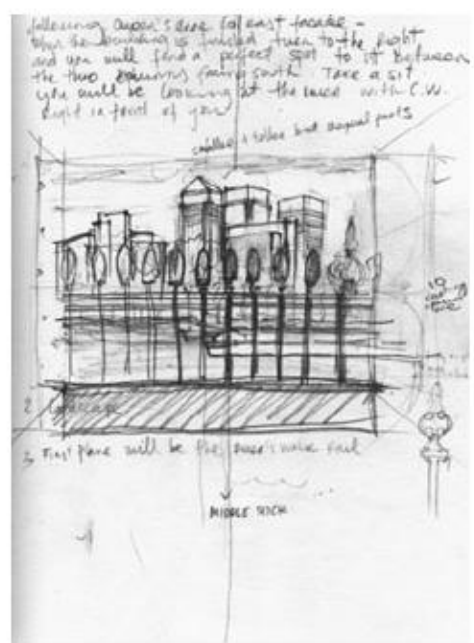

By Adriana Cobo

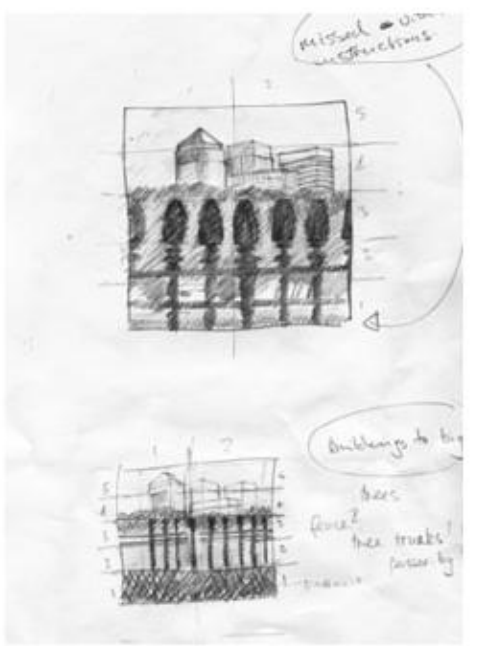

By Elinor Stewart

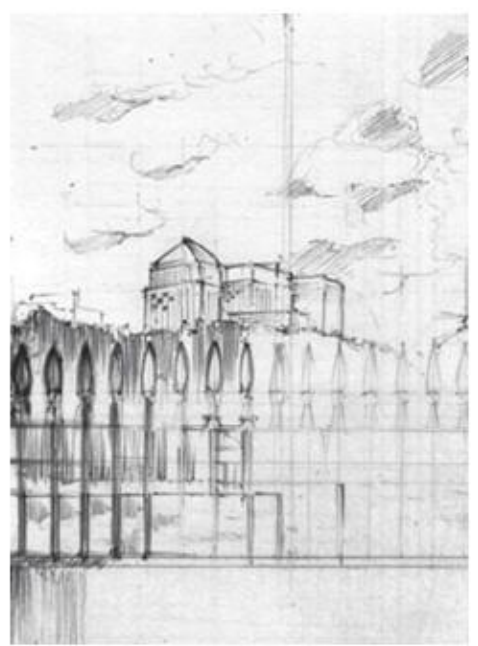

By Neal Fairman

\section{Conclusions}

Drawing is the architect's main tool for representing ideas and as such is a key skill to develop from the beginning of an architecture degree. Architects design through drawing. All buildings and projects start as sketches. Learning how to draw requires ongoing practice and a great deal of time. New students need to be taught how to represent what they see. To observe space, buildings and objects is the first step towards learning how to draw. Looking at things with an 'architect's eye' is key for achieving representational skills. Guided observation and constant repetition are important tutoring tools, especially throughout the first stages of the learning process. Tutorial time is never sufficient, particularly when it comes to teaching drawing, so the guide is intended to contribute additional tutorial time for observational drawing and is to be used freely by students. Drawing is 
equally a skill that can be taught, but is also an individual discovery. The Parrot Brief addresses both.

\section{General reflections on methodology}

The introduction of new ways of teaching using blended forms of learning does cause some concerns:

- Does basing the guide on a set of prescribed, precise instructions from a single tutor work against individual expression?

- Does the more traditional 'trial and error' methodology, based on a high level of tutor contact time, achieve better results in the long run?

- Are these questions relevant to other professional disciplines which are not design-related?

When presenting the guide at last year's Engaging Students Annual Learning and Teaching Conference 2009 at the University of Greenwich, to a group of colleagues from different Schools, I discovered similarities with staff teaching first-year undergraduates in law. In the case of law, steps for analysing a law case are given to students in the form of printed briefs. Using these, students develop their own views. This was a pleasant surprise and it raised the possibility of employing an audio guide as a teaching methodology for non-design related disciplines. In the case of law, some essential steps for analysing a law case are given to students in the form of printed briefs. Using these, students develop their own views. Similarly, podcasting for understanding and decoding a poem could become a tool for teaching English, basic steps for studying body structures could become a tool for teaching forensic science or anatomy, and so on...

In general, although my background is in a discipline which incentivises individual creativity, I have seen how a prescribed structure for performing a task yields interesting results, especially in the early stages of learning.

\section{Where to find the guide}

Please visit www.digitalstudio.gre.ac.uk. Or go to the Avery Hill library and ask for the Parrot Brief.

\section{References}

Adjmi, M. and Bertoletto, G. (eds.) (1993) Aldo Rossi: Drawings and Paintings. New York: Princeton Architectural.

Blake, Q. and Cassidy, J. (1999) Drawing, for the Artistically Undiscovered. USA: Klutz. 